\title{
Non-verbal semantic impairment in semantic dementia
}

\author{
Sasha Bozeat ${ }^{\mathrm{a}}$, Matthew A. Lambon Ralph ${ }^{\mathrm{a}, *}$, Karalyn Patterson ${ }^{\mathrm{a}}$, Peter Garrard ${ }^{\mathrm{b}}$, \\ John R. Hodges ${ }^{\mathrm{a}, \mathrm{b}}$ \\ ${ }^{a}$ MRC Cognition and Brain Sciences Unit, 15 Chaucer Road, Cambridge CB2 2EF, UK \\ ' University Neurology Unit, Addenbrooke's Hospital, Cambridge, UK
}

Received 11 October 1999; received in revised form 8 February 2000; accepted 14 February 2000

\begin{abstract}
The clinical presentation of patients with semantic dementia is dominated by anomia and poor verbal comprehension. Although a number of researchers have argued that these patients have impaired comprehension of non-verbal as well as verbal stimuli, the evidence for semantic deterioration is mainly derived from tasks that include some form of verbal input or output. Few studies have investigated semantic impairment using entirely non-verbal assessments and the few exceptions have been based on results from single cases ([3]: Breedin SD, Saffran EM, Coslett HB. Reversal of the concreteness effect in a patient with semantic dementia. Cognitive Neuropsychology 1994;11:617-660, [12]: Graham KS, Becker JT, Patterson K, Hodges JR. Lost for words: a case of primary progressive aphasia? In: Parkin A, editor. Case studies in the neuropsychology of memory, East Sussex: Lawrence Erlbaum, 1997. pp. 83-110, [21]: Lambon Ralph MA, Howard D. Gogi aphasia or semantic dementia? Simulating and assessing poor verbal comprehension in a case of progressive fluent aphasia. Cognitive Neuropsychology, (inpress).

This study employed sound recognition and semantic association tasks to investigate the nature of the verbal and non-verbal comprehension deficit in 10 patients with semantic dementia. The patients were impaired on both verbal and non-verbal conditions of the assessments, and their accuracy on these tasks was directly related to their scores on a range of other tests requiring access to semantic memory. Further analyses revealed that performance was graded by concept and sound familiarity and, in addition, identified significant item consistency across the different conditions of the tasks. These results support the notion that the patients' deficits across all modalities were due to degradation within a single, central network of conceptual knowledge. There were also reliable differences between conditions. The sound-picture matching task proved to be more sensitive to semantic impairment than the word-picture matching equivalent, and the patients performed significantly better on the picture than word version of a semantic association test. We propose that these differences arise directly from the nature of the mapping between input modality and semantic memory. Words and sounds have an arbitrary relationship with meaning while pictures benefit from a degree of systematicity with conceptual knowledge about the object. (C) 2000 Elsevier Science Ltd. All rights reserved.
\end{abstract}

Keywords: Semantic dementia; Progressive fluent aphasia; Frontotemporal dementia; Non-verbal comprehension; Conceptual knowledge

\section{Introduction}

The syndrome of semantic dementia is associated with circumscribed temporal lobe atrophy, most

\footnotetext{
* Corresponding author. Tel.: +44-1223-355294.

E-mail address: matt.lambon-ralph@mrc-cbu.cam.ac.uk (M.A. Lambon Ralph).
}

severely affecting the temporal pole and the infero-lateral temporal lobe, typically bilaterally but often asymmetrically $[14,33]$. The ventromedial frontal cortex bilaterally and the amygdaloid complex are also often affected $[25,26]$. The term semantic dementia was proposed because the cases have a selective and progressive deterioration of conceptual knowledge. The selective nature of the semantic impairment was first described by Warrington [35], who reported three 
patients with progressive anomia and impaired word comprehension. More recent studies have highlighted the patients' progressive loss of knowledge about the meanings of words, objects and concepts $[13,33]$. The selective nature of the semantic deficit in these patients has been confirmed by their good performance on assessments of current day-to-day memory, short-term verbal memory, visuospatial skills, non-verbal reasoning, phonology and syntax until very late in the course of the disease [14].

The clinical presentation of semantic dementia is dominated by anomia and poor verbal comprehension, to the extent that the term 'Gogi', or word meaning aphasia, is sometimes used to describe these patients in Japan [17,30]. Imura et al. [18] and Tanabe et al. [34] emphasised that the impairment in Gogi aphasia is limited to the domain of language. In this regard, Tanabe et al. noted comments from the wife of a patient who was surprised that her husband could no longer understand the names of objects that he still used efficiently everyday [34]. Although it has been argued that patients with semantic dementia have degraded knowledge for non-verbal as well as verbal stimuli $[14,33]$, the evidence for a non-verbal semantic impairment has tended to rely upon tasks that include verbal input (e.g., word-to-picture matching and drawing of objects to dictation of their names) or output (e.g., picture naming, definitions of pictured concepts, descriptions of famous people from face stimuli, etc).

The existing literature contains limited examples of entirely non-verbal assessment of comprehension, the vast majority of which rely on pictures to probe knowledge. A number of researchers have reported impairment on the picture version of the Pyramid and Palm Trees test [15], which is a non-verbal assessment of semantic associations [3,20,23,31]. Breedin et al. [3] assessed a patient on colouring of black and white line drawings of objects and animals that have a specific known colour. The patient showed severe impairment on this task, being able to select the correct colour for only 10 out of 28 items. Using similar colouring tasks, both Graham et al. [12] and also Lambon Ralph, Howard, Nightingale and Ellis [22] demonstrated nonverbal semantic impairments in single case studies of patients with semantic dementia.

In addition to picture based tests, sound recognition tasks can also provide a straightforward, non-verbal assessment of comprehension. Sound recognition has been assessed in one case with herpes simplex virus encephalitis (HSVE) but it has been used most often to test patients with pure word deafness $[1,6]$. Rather than requiring a subject to identify an object or animal by naming it in response to its characteristic sound, Lambon Ralph and Howard [21] formulated a nonverbal assessment by asking the patient to match the sound to a picture of the target concept. The semantic dementia patient IW was impaired on both this soundto-picture test and a corresponding sound-to-word version thereby confirming the presence of a non-verbal semantic impairment [21].

The aim of this cross-sectional study was to provide further evidence for the non-verbal conceptual impairment in semantic dementia based on a larger set of patients and a more extended investigation than in previous studies. In addition to a battery of standard assessments of comprehension, including the Pyramids and Palm Trees test, recognition of environmental sounds and a new semantic association task were used to test the patients' semantic memory non-verbally.

\section{Method}

\subsection{Participants}

Ten patients were identified through the Memory and Cognitive Disorders Clinic at Addenbrooke's Hospital, Cambridge, UK, where they were seen by a senior neurologist (JRH), a senior psychiatrist and a clinical neuropsychologist. In addition to a clinical assessment, all patients were given a number of standard psychiatric rating scales to exclude major functional psychiatric disorders such as depression and schizophrenia. They all underwent CT or MRI scanning together with the usual battery of screening blood tests to exclude treatable causes of dementia.

All patients presented with a progressive loss of vocabulary affecting expressive and receptive language in the context of fluent speech production. They all fulfilled the criteria for semantic dementia previously reported: anomia, impairment in single word comprehension and impoverished semantic knowledge with relative preservation of phonology, syntax, visuospatial abilities and day-to-day memory [13,14]. Structural brain imaging by MRI showed focal atrophy involving the polar and inferolateral regions of one or both of the temporal lobes.

To compare the performance of the patients with that of age and education matched controls, we selected normal participants from the Medical Research Council Cognition and Brain Sciences Unit's participant panel.

\subsection{Assessments}

\subsubsection{General neuropsychology}

The following battery of neuropsychological tests was administered: the Mini-Mental State Examination as a general measure of cognitive impairment [8], the digit span subtest of the Wechsler Memory ScaleRevised (WMS-R) [38] to assess auditory-verbal short term memory; verbal fluency for the letters F, A, S to 
test executive function; the Raven's advanced or coloured matrices to assess non-verbal problem solving $[27,28]$; copy and immediate recall of the Rey Complex Figure to test visuospatial skills and episodic memory [29]. Various subtests from the Visual Object and Space Perception battery were also used to assess visuospatial function in more detail [36].

\subsubsection{Semantic tests}

2.2.2.1. General semantic assessment. The patients were given a selection of tasks from a semantic battery, which is a collection of tests that use the same set of stimulus items to assess semantic knowledge systematically across different input and output modalities. It contains 64 items, chosen from the corpus of line drawings by Snodgrass and Vanderwart [32], representing three categories of living things (animals, birds and fruit) and three categories of artefacts (household items, tools and vehicles). The following subtests from the semantic battery were administered: category fluency, in which the subject is asked to produce as many exemplars as possible in one minute for each of the six categories; naming of the 64 line drawings; spoken word-to-picture matching using picture arrays containing the target plus nine within-category foils.

Two other semantic assessments were also administered: the concrete and abstract word synonym test which requires the subject to choose one of two words that is similar in meaning to the target word [37] and the Pyramids and Palm Trees test [15] of associative semantic knowledge. In this later assessment, subjects are asked to choose one of two items that is most closely associated with the target (e.g., for the target pyramid, the choice is between palm tree and pine tree). The stimuli are presented as either pictures or written words.

2.2.2.2. Camel and Cactus test. Two new semantic assessments were designed specifically for this study. The first was a test of semantic association based on the principle of the Pyramids and Palm Trees test [15]. Subjects were asked to choose one of four same-category items that has an associative relationship with the target. For example, in one of the trials the subject was asked to match a camel to one of four types of vegetation: cactus (the target), tree, sunflower or rose. The target items for this test were the same 64 items as those included in the battery of semantic tests described above. The assessment was administered in two forms: in one, all items (targets and response choices) were presented as pictures; in the other form, all stimuli were words. Concept familiarity ratings from a previous study [10] were already available for the 64 target items included in the Camel and Cactus test.
2.2.2.3. Environmental Sounds test. This test was based on the sound matching assessment used by Lambon Ralph and Howard [21]. It contained 48 sounds from six categories (domestic animals, foreign animals, human sounds, household items, vehicles and musical instruments). Some less familiar sounds were included in an attempt to create a more sensitive measure of early semantic impairment. There were three conditions: matching sounds to pictures, sounds to written words and spoken words to picture. Subjects were asked to listen on each trial to a sound or a spoken word and match it to the target stimulus (picture or written word) from an array of 10 within-category items.

Familiarity with the items was established by asking 20 normal participants to rate both their overall familiarity with each item and how often they hear each sound on a scale of 0 (never) to 6 (every hour), leading to a measure for familiarity with both the concept in general and the sound specifically.

\section{Results}

\subsection{General neuropsychology}

The 10 patients covered a broad spectrum of impairment as indicated by their performance on the MiniMental State Examination (see Table 1). They all showed intact working memory as measured by forward and backward digit span. Although DC performed worse than expected on the backward digit span, this was probably due to a failure to comprehend the task. All patients exhibited some impairment on the letter fluency test. There was general preservation of non-verbal problem-solving skills as measured by Raven's matrices. It should be noted that as two versions of the Raven's matrices were used, the advanced and the coloured, the scores are given as percentiles. The two patients, JC and WM, who performed below the level of the other patients were both given the advanced version of the test which is particularly difficult. All patients had preserved visuospatial skills as indicated by their copying of the Rey Figure and performance on the various subtests of the Visual Object and Space Perception battery. Recall of the Rey Figure was good in all cases revealing preservation of non-verbal episodic memory.

\subsection{Semantic tests}

\subsubsection{General semantic assessment}

As shown in Table 2, the patients included in this study also covered a wide range of semantic decline from the mildly impaired patients such as JP through to IF. All showed reduced category fluency and some 
Table 1

General neuropsychology

\begin{tabular}{|c|c|c|c|c|c|c|c|c|c|c|c|}
\hline Test (maximum score) & JP & WM & SL & $\mathrm{JC}$ & DS & AT & $\mathrm{DC}$ & JW & $\mathrm{JH}$ & IF & $\begin{array}{l}\text { Control } \\
\text { mean } \\
(\mathrm{SD})\end{array}$ \\
\hline MMSE (30) & 29 & 27 & 28 & 24 & 23 & 25 & 18 & NT & 9 & 11 & $28.8(0.5)$ \\
\hline \multicolumn{12}{|l|}{ Digit span } \\
\hline forward & 6 & 8 & 6 & 8 & 6 & 8 & 7 & 5 & 6 & 5 & $6.8(0.9)$ \\
\hline backward & 5 & 7 & 3 & 4 & 4 & 5 & 2 & 5 & 5 & 5 & $4.7(1.2)$ \\
\hline Letter fluency (total: FAS) & 27 & 29 & 31 & 23 & 7 & 20 & 16 & NT & 19 & 16 & $44.2(11.2)$ \\
\hline Raven's matrices (percentiles) & $>95^{\mathrm{a}}$ & $50^{\mathrm{b}}$ & NT & $25^{\mathrm{b}}$ & $95^{\mathrm{a}}$ & $90^{\mathrm{a}}$ & $>95^{\mathrm{a}}$ & $>95^{\mathrm{a}}$ & $90^{\mathrm{a}}$ & $90^{\mathrm{a}}$ & \\
\hline \multicolumn{12}{|l|}{ Rey Figure } \\
\hline copy (36) & 35 & 35 & 30 & 30 & 35 & 28 & 32 & 36 & 36 & 26 & $34(2.9)$ \\
\hline immediate recall & 23.5 & 24 & 15.5 & NT & 17.5 & 14 & 12 & NT & 10.5 & NT & $18.3(5.2)$ \\
\hline \multicolumn{12}{|l|}{ VOSP } \\
\hline incomplete letters (20) & NT & 19 & 20 & 20 & 20 & NT & 20 & 20 & 18 & NT & $19.2(0.8)$ \\
\hline dot counting $(10)$ & 10 & 10 & 10 & 10 & 10 & 10 & 10 & 10 & 10 & 10 & $9.9(0.3)$ \\
\hline position discrimination (20) & NT & 20 & NT & 20 & 20 & NT & 17 & NT & 20 & 20 & $19.8(0.6)$ \\
\hline cube analysis (10) & NT & 10 & NT & 9 & 10 & NT & 10 & NT & 10 & 6 & $9.7(2.5)$ \\
\hline number location (10) & 10 & 9 & 10 & 10 & 9 & 10 & 10 & NT & 10 & NT & $8.9(2.8)$ \\
\hline
\end{tabular}

Patients are ordered according to their performance on the naming and the category comprehension tests (see Table 2). VOSP - Visual Object and Space Perception battery.

${ }^{a}$ Raven's coloured progressive matrices.

b Raven's advanced progressive matrices.

NT - not tested.

degree of anomia as indicated by their performance on the naming test. All patients, except for WM and JP were impaired on comprehension as measured by the word-to-picture matching (N.B. the patients in Tables 1 and 2 are ordered as best as possible to reflect decreasing naming and comprehension scores). The patients performed very poorly on the concrete and abstract word synonym test. Apart from WM, the synonym scores were no better than expected by chance, revealing this assessment to be a highly sensitive measure of semantic impairment. The patients were impaired on both conditions of the Pyramids and Palm trees test, except for JP and WM who performed within the normal range on the picture version. Before considering the results of the Camel and Cactus test and the Environmental Sounds test, we note that the patients tended to achieve similar scores for both the non-verbal and verbal versions of the Pyramids and Palm Trees test, supporting the view that they have a generalised semantic impairment affecting all modalities of input. In this regard it is important to note that significant correlations were found between the patients' scores for all the semantic tasks ( $r$ between 0.75 and 0.94 , all $p_{\text {one-tailed }}<0.05$ ) except for the concrete and abstract word synonyms, which is not surprising given the almost uniformly chance level of performance on this test.

\subsubsection{Camel and Cactus test}

Looking at the patients individually, it is clear that eight out of 10 were impaired on the Camel and Cac- tus test when compared to controls, the exception being WM who scored at the bottom of the normal range on the picture version and JP who scored within the normal range on both conditions (see Fig. 1). As noted earlier, these two patients were in the early stages of semantic dementia and their mild semantic deficit was only revealed by certain assessments.

An analysis of variance was used to investigate the differences in performance of patients and controls for the two different conditions of this test. This analysis revealed a significant main effect of group, with the patients performing worse than controls $(F(1,27)=10.81, p<0.01)$; there was no main effect of condition $(F(1,27)<1)$ but a significant interaction between group and condition $(F(1,27)=4.18$, $p=0.05$ ). Post hoc paired-samples $t$-tests revealed that the patients performed significantly better on the picture than the word condition of this test (pictures: mean - 40.6 (SD - 13.9), words: mean - 37 (SD $\left.16.25) ; \quad t_{(7)}=2.93, \quad p<0.05\right)$. The small difference favouring the word condition for the control subjects was not statistically reliable (pictures: mean - 56.9 (SD - 7.27), words: mean -59.1 (SD - 6.3); $t_{(19)}=1.16$, n.s).

Scores on the picture condition of the Camel and Cactus test were significantly correlated with all the semantic measures in Table 2, except the concrete and abstract word synonym test $(r$ between 0.88 and 0.95 , all $\left.p_{\text {one-tailed }}<0.01\right)$. Performance on the word condition also correlated with the same semantic assessments $\left(r\right.$ between 0.77 and 0.88 , all $p_{\text {one-tailed }}<0.05$ ). 
Table 2

Assessment of semantic memory

\begin{tabular}{|c|c|c|c|c|c|c|c|c|c|c|c|}
\hline Test (maximum score) & JP & WM & SL & $\mathrm{JC}$ & DS & AT & DC & JW & $\mathrm{JH}$ & IF & $\begin{array}{l}\text { Control } \\
\text { mean } \\
(\mathrm{SD})\end{array}$ \\
\hline \multicolumn{12}{|l|}{ Category fluency } \\
\hline living & 42 & 38 & 23 & 15 & 3 & 14 & 6 & 3 & 5 & 2 & $60.3(12.6)$ \\
\hline manmade & 37 & 29 & 20 & 21 & 10 & 18 & 4 & 4 & 7 & 5 & $54.8(10.3)$ \\
\hline Naming (64) & 59 & 57 & 45 & 43 & 17 & 17 & 11 & 9 & 6 & 1 & $62.3(1.6)$ \\
\hline Word-picture matching (64) & 64 & 63 & 60 & 58 & 58 & 57 & 36 & 23 & 18 & 18 & $63.7(0.5)$ \\
\hline \multicolumn{12}{|l|}{ Word synonyms } \\
\hline concrete $(25)$ & $13^{\mathrm{a}}$ & 21 & $15^{\mathrm{a}}$ & $12^{\mathrm{a}}$ & $12^{\mathrm{a}}$ & 16 & $14^{\mathrm{a}}$ & NT & $12^{\mathrm{a}}$ & $13^{\mathrm{a}}$ & $23.7(1.3)$ \\
\hline abstract $(25)$ & $14^{\mathrm{a}}$ & 18 & $15^{\mathrm{a}}$ & $8^{a}$ & $14^{\mathrm{a}}$ & $14^{\mathrm{a}}$ & $13^{\mathrm{a}}$ & NT & $13^{\mathrm{a}}$ & $13^{\mathrm{a}}$ & $23.0(2.1)$ \\
\hline \multicolumn{12}{|l|}{ Pyramids and Palm Trees } \\
\hline words (52) & 48 & 48 & 46 & 44 & 46 & 45 & $25^{\mathrm{a}}$ & 32 & $25^{\mathrm{a}}$ & $28^{\mathrm{a}}$ & $51.1(1.1)$ \\
\hline pictures $(52)$ & 49 & 52 & 48 & 41 & 46 & 47 & 36 & $27^{\mathrm{a}}$ & 37 & $22^{\mathrm{a}}$ & $51.2(1.4)$ \\
\hline
\end{tabular}

${ }^{a}$ Score not significantly better than expected by chance.

3.2.2.1. Item consistency. As noted in the Introduction, the term semantic dementia implies a selective and gradual impairment to a single central system of conceptual knowledge, leading to impairments in all tasks that require activation of such knowledge, whether they involve verbal or non-verbal input or output modalities. If this is the case, performance on different semantic assessments should not only be correlated but, where the same terms/concepts are used, patients should exhibit significant item consistency across the different modalities tested. Item consistency across the two conditions of the Camel and Cactus test was investigated using a series of simultaneous logistic regression analyses.

Assessment of item consistency is complicated by the fact that some items are invariably harder than others. Specifically, performance in semantic dementia is known to be affected by the familiarity of each concept $[9,19]$. One would therefore expect to find some consistency simply on the basis that unfamiliar items will tend to be consistently inaccurate, and more familiar items consistently accurate $[2,5,16,21]$. Consistency between the picture and word conditions was assessed by predicting the former from the latter, and vice versa, with two additional predictor variables included in the regression equation: familiarity and patient. The possibility that consistency may vary across individual patients was assessed by repeating each regression analysis with an interactive term, patient by predicting task, included. The two patients who performed at chance on one or both versions of the Camel and Cactus test, IF and DC, were not included in the consistency analysis.

These analyses revealed significant consistency across the two conditions (Wald values 30.61 and 30.99 , both $p<0.001)$. Performance was significantly affected by familiarity only in the word version of the test $\quad($ Wald $=11.64, \quad p<0.001)$. Accuracy varied between patients (Wald values 20.01 and 73.18 , both $p<0.05)$, but there was no indication that consistency varied across subjects (Wald values 0.83 and 1.08, n.s).

\section{Camel and Cactus Test (pictures)}

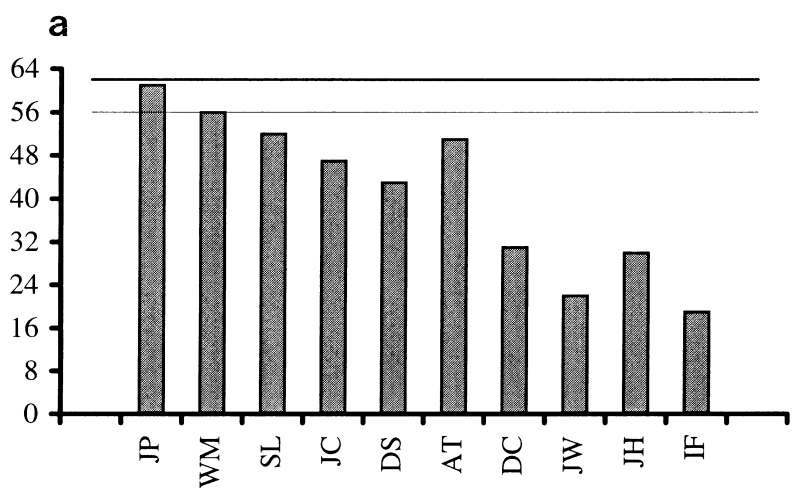

Camel and Cactus Test (words)

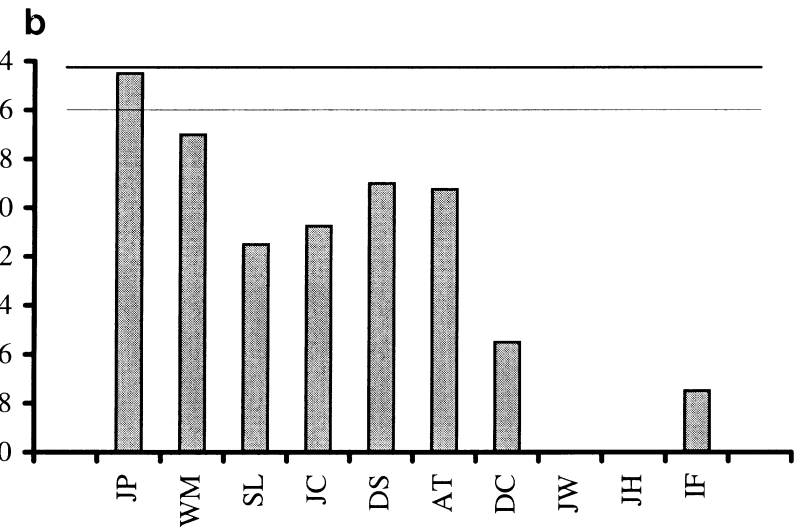

Fig. 1. (a) Performance on the picture condition of the camel and cactus test. The two horizontal lines denote the upper and lower limits of normal performance. (b) Performance on the word condition of the camel and cactus test. The two horizontal lines denote the upper and lower limits of normal performance. Data are not available for JW and $\mathrm{JH}$. 


\subsubsection{Environmental Sounds test}

Looking at the patients individually, it is clear that they all scored outside the normal range on all conditions of the Environmental Sounds test except for WM, whose score fell below normal on sound-to-word matching only (see Fig. 2).

Analysis of variance revealed a significant main effect of group, with the patients performing worse than the control subjects $(F(1,24)=68.01, p<0.001)$; there was a main effect of condition $(F(2,48)=81.36$, $p<0.001)$ and an interaction between group and condition $(\mathrm{F}(2,48)=8.71, p<0.01)$, which arose from a larger difference between word-to-picture matching and the two conditions requiring sound recognition in the patients than in the controls (patients: word-picture: mean - 33.3 (SD - 11.64), sound-picture: mean - 21.6 (SD - 8.69), sound-word: mean 19.8 (SD - 7.89); controls: word-picture: mean 47.75 (SD - 0.57), sound-picture: mean - 41.18 (SD - 2.54), sound-word: mean - 41.25 (SD - 2.74)). Paired-samples $t$-tests confirmed that both the patients and controls performed significantly better on the word-to-picture matching condition compared to both of the sound conditions ( $t$ values between 4.91 and 9.97, all $p<0.001$ ). There was no significant difference between sound-to-picture matching and sound-to-word matching (patients: $t_{(9)}=1.57, \quad$ n.s; controls: $t_{(17)}=0.92$, n.s).

Significant correlations were found between the patients' scores for all conditions of this test, the semantic battery tests and the Camel and Cactus test (between 0.73 and 0.97 , all $p_{\text {one-tailed }}<0.05$ ), though not with the concrete and abstract synonym test. The correlation between sound-to-picture matching and the word condition of the Camel and Cactus test just failed to reach significance $\left(r=0.59, p_{\text {one-tailed }}=0.06\right)$.

3.2.3.1. Item consistency. Consistency between the three conditions of the Environmental Sounds test was also measured by a series of simultaneous logistic regression analyses. For example, consistency between the sound-to-picture and sound-to-word conditions was assessed by predicting the former from the latter, and then repeated the other way around, with two additional predictor variables included in the regression equation: familiarity (either general familiarity or sound familiarity) and patient. The possibility that consistency may vary across individual patients was tested by repeating each regression analysis with an interactive term, patient by predicting task, included.

Performance was significantly consistent across all possible pairings of the three conditions (Wald values between 13.16 and 34.67 , all $p<0.001$ ). Accuracy was affected by familiarity, whether measured as the familiarity with the sound (Wald values between 4.65 and 11.87, all $p<0.05$ ) or familiarity in general (Wald values between 4.26 and 48.26, all $p<0.05$ ). The one exception to this summary is that, when predicting performance on the word-to-picture matching task from performance on sound-to-picture matching, the effect of general familiarity failed to reach significance (Wald $=2.94, p=0.08)$. Accuracy varied significantly between the patients (Wald values between 18.83 and 39.45 , all $p<0.001$ ), but there was no indication that consistency varied across subjects (Wald values between 0.01 and 23.89 , n.s).

\section{Environmental Sounds Test (sound-picture)}

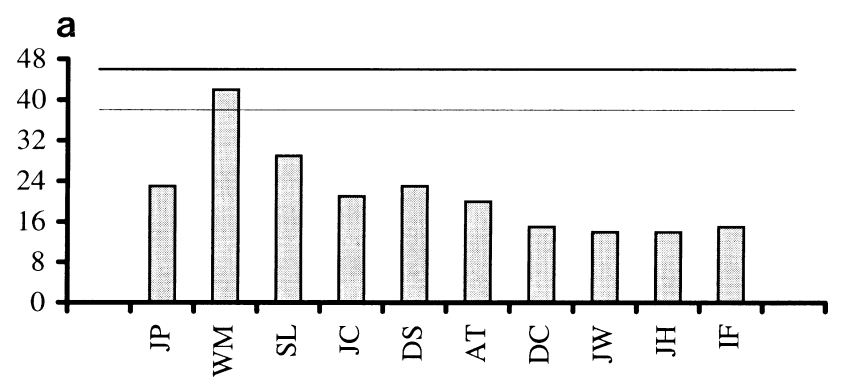

Environmental Sounds Test (sound-word)

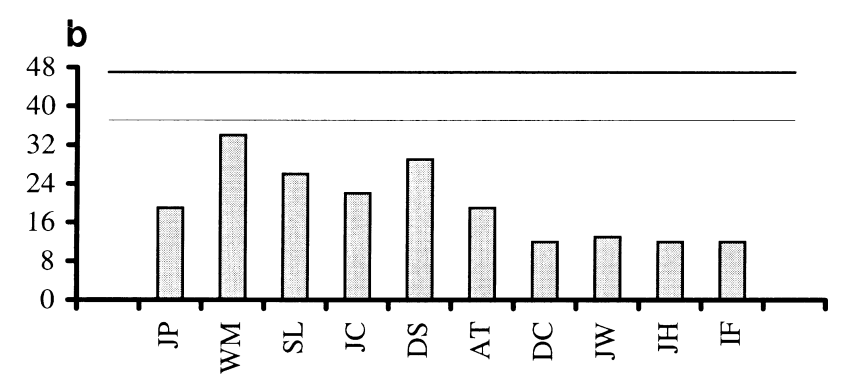

Environmental Sounds Test (word-picture)

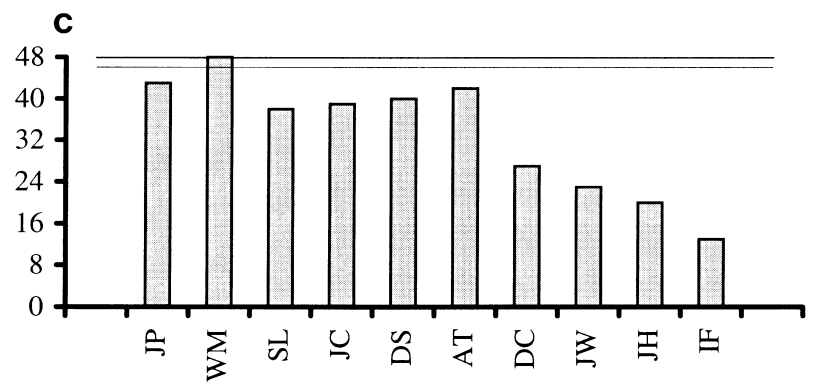

Fig. 2. (a) Performance on the sound-to-picture matching test. The two horizontal lines denote the upper and lower limits of normal performance. (b) Performance on the sound-to-word matching test. The two horizontal lines denote the upper and lower limits of normal performance. (c) Performance on the word-to-picture matching test. The two horizontal lines denote the upper and lower limits of normal performance. 


\section{Discussion}

The aim of this study was to demonstrate that the key impairment in semantic dementia is not simply a word comprehension deficit but a generalised deterioration of semantic memory that extends to the nonverbal domain. Overall, the patients performed significantly below the control subjects on both the picture version of the Camel and Cactus test and the soundto-picture matching condition of the Environmental Sounds test. These results provide clear evidence that comprehension is impaired in semantic dementia even in tasks where neither stimuli nor responses contain or require any words. Significant correlations were found between the patients' scores on all the semantic tests as well as item consistency across the different modalities of the Camel and Cactus test and the Environmental Sounds test, even after controlling for the familiarity of the items. Altogether, this evidence provides strong support for the notion that semantic dementia is best characterised as a progressive impairment to central conceptual knowledge, that supports semantic performance independent of modality.

Further analysis also revealed reliable differences between modalities. The patients performed significantly better on the picture than word condition of the Camel and Cactus test, a result that was not echoed in the control group. On the Environmental Sounds test, both the patients and controls were more successful on the word-to-picture matching condition than either of the sound conditions, though the difference was greater in the patients than the controls. There were no differences in either group between matching sounds to pictures and sounds to words.

There is no puzzle in the pattern of correlations between tests and consistency between items across different conditions combined with differences in performance on the different conditions. This pattern is easily explicable in terms of the notion that partially degraded knowledge will have differential effects on overt performance depending on the nature of the mapping between input/output modalities and conceptual knowledge. Information available directly from the perception of pictures and objects provides clues to both form and function [11]. Gibson's notion of affordance [11] has some overlap with the theories of Caramazza and colleagues [4], who propose firstly, that objects benefit from direct access to meaning from visual input (the assumption of privileged access) and, secondly, that knowledge about the structural aspects of an object is closely linked to the semantic properties that specify its function (the assumption of privileged relationships). A similar proposal can be found in the literature on category specific deficits [6,7]. At a computational level of description, this can be cast in terms of the systematicity of the mapping between different representations. Systematicity can be thought of in terms of how well features of the input are able to predict output patterns. In a perfectly systematic mapping, each output feature can be predicted by a corresponding input feature, whereas in an arbitrary mapping, there is no such predictability.

Lambon Ralph and Howard [21] used a simple connectionist simulation to demonstrate the impact of different mappings between surface form and conceptual knowledge. Following simulated damage to the semantic system, comprehension performance was always better when semantic representations were activated by picture than by word input. Furthermore, even when the network made comprehension errors, these nearly always involved activation of the correct semantic region for pictures but this was much less likely to occur for words. In this simulation only a portion of the full distributed semantic representation was related systematically to the picture representation. When the quality of the two parts of the conceptual representation was compared, both exhibited a significant difference, favouring picture over word input. This would seem to suggest that even limited systematicity between input modality and a minor part of the full semantic pattern is likely to benefit comprehension in general.

Further support for the differential effects of systematic and arbitrary mapping comes from another simulation reported by McGuire and Plaut [24]. They found that task systematicity had a dramatic effect on the rate of acquisition and the robustness of the system to damage. For example, when just $1 \%$ of the connections were removed there was no effect on the task supported by a systematic mapping, but, this level of damage reduced correct performance to $78 \%$ on the task underpinned by arbitrary mapping.

These computational models, like the patients described here, exhibit impaired comprehension of both word and picture stimuli as well as a significant difference in accuracy favouring the pictures. The networks demonstrate that such a difference should be expected following impairment to a unitary semantic system because the arbitrary mapping underlying word comprehension is relatively sensitive to mild levels of damage.

Although the discussion of these networks has been cast only in terms of picture and word comprehension, the same argument can be applied to explain performance on the sound recognition tests. Even the two mildest patients included in this study (JP and WM), who did not show much impairment on the other semantic tests, had scores outside the normal range on one or both conditions of the sound recognition task, suggesting that this assessment is very sensitive to early/mild semantic impairment. We propose that there may be two factors underlying this finding. 
Sounds, like words, have more of an arbitrary relationship with their meaning than pictures do and this makes them vulnerable to mild levels of semantic impairment. Unlike words, however, we are not often required to access meaning solely from the sound of an object. We are more accustomed to hearing a sound and seeing the animal or object at the same time. Indeed we know from this and previous studies $[9,19]$ that familiarity is an important predictor of performance in these cases, and so it is important to note that the ratings of familiarity with the sound of an item were significantly lower than for the concept as a whole $\left(t_{(47)}=2.17, p<0.05\right)$. A test involving the combination of sounds and words as stimuli, therefore, creates a particularly difficult situation for the patients with semantic dementia because both have a largely arbitrary mapping to meaning, and the sounds are, on the whole, relatively unfamiliar.

\section{Acknowledgements}

We are indebted to the continuing support of the patients included in this study. This research is supported by grants from the Medical Research Council (UK) and the National Institutes of Health (USA).

\section{References}

[1] Auerbach SH, Allard T, Naeser M, Alexander MP, Albert ML. Pure word deafness: analysis of a case with bilateral lesions and a defect at the prephonemic level. Brain 1982;105:271-300.

[2] Behrmann M, Bub D. Surface dyslexia and dysgraphia: dual routes, single lexicon. Cognitive Neuropsychology 1992;9:20951.

[3] Breedin SD, Saffran EM, Coslett HB. Reversal of the concreteness effect in a patient with semantic dementia. Cognitive Neuropsychology 1994;11:617-60.

[4] Caramazza A, Hillis AE, Rapp BC, Romani C. The multiple semantics hypothesis: multiple confusions? Cognitive Neuropsychology 1990;7:161-89.

[5] Coltheart M, Funnell E. Reading and writing: one lexicon or two? In: Allport DA, MacKay W, Prinz W, Scheerer E, editors. Language perception and production: shared mechanisms in listening, reading and writing. London: Academic Press, 1987. p. 313-39.

[6] De Renzi E, Lucchelli F. Are semantic systems separately represented in the brain? The case of living category impairment. Cortex 1994;30:3-25.

[7] Durrant-Peatfield M, Tyler LK, Moss HE, Levy JI. The distinctiveness of form and function in category structure: a connectionist model. In: Proceedings of the Nineteenth Annual Conference of the Cognitive Science Society. Stanford University. Mahwah, NJ: Erlbaum, 1997. p. 193-8.

[8] Folstein MF, Folstein SE, McHugh PR. "Mini-mental state": a practical method for grading the mental state of patients for clinicians. Journal of Psychiatric Research 1975;12:189-98.

[9] Funnell E. From objects to properties: evidence for spreading semantic activation in a case of semantic dementia. Memory 1995;3:497-519.
[10] Garrard P, Lambon Ralph MA, Hodges JR, Patterson K. Prototypicality, distinctiveness and intercorrelation: analyses of the semantic attributes of living and nonliving concepts. Cognitive Neuropsychology, submitted.

[11] Gibson JJ. The theory of affordances. In: Shaw R, Bransford J, Hillsdale NY, editors. Perceiving, acting and knowing: toward an ecological psychology. New York: Lawrence Erlbaum Associates, 1977. p. 67-82.

[12] Graham KS, Becker JT, Patterson K, Hodges JR. Lost for words: a case of primary progressive aphasia? In: Parkin A, editor. Case studies in the neuropsychology of memory. East Sussex: Lawrence Erlbaum, 1997. p. 83-110.

[13] Hodges JR, Graham N, Patterson K. Charting the progression in semantic dementia: implications for the organisation of semantic memory. Memory 1995;3:463-95.

[14] Hodges JR, Patterson K, Oxbury S, Funnell E. Semantic dementia: progressive fluent aphasia with temporal lobe atrophy. Brain 1992;115:1783-806.

[15] Howard D, Patterson K. Pyramids and palm trees: a test of semantic access from pictures and words. Bury St Edmunds, Suffolk: Thames Valley Test Company, 1992.

[16] Howard D, Patterson K, Franklin S, Orchard-Lisle V, Morton J. The facilitation of picture naming in aphasia. Cognitive Neuropsychology 1985;2:49-80.

[17] Imura T. Aphasie: characteristic symptoms in Japanese. Psychiatra et Neurologia Japonica 1943;47:196-218.

[18] Imura T, Nogami Y, Asakawa K. Aphasia in Japanese language. Nihon University Journal of Medicine 1971;13:69-90.

[19] Lambon Ralph M, Graham KS, Ellis A, Hodges JR. Naming in semantic dementia - what matters? Neuropsychologia 1998;36:775-84.

[20] Lambon Ralph M, Graham KS, Patterson K, Hodges JR. Is a picture worth a thousand words? Evidence from concept definitions by patients with semantic dementia. Brain and Language 1999;70:309-35.

[21] Lambon Ralph MA, Howard D. Gogi aphasia or semantic dementia? Simulating and assessing poor verbal comprehension in a case of progressive fluent aphasia. Cognitive Neuropsychology, in press.

[22] Lambon Ralph MA, Howard D, Nightingale G, Ellis AW. Are living and non-living category-specific deficits causally linked to impaired perceptual or associative knowledge? Evidence from a category-specific double dissociation. Neurocase 1998:4:311-38.

[23] Lauro-Grotto R, Piccini C, Shallice T. Modality-specific operations in semantic dementia. Cortex 1997;33:593-622.

[24] McGuire S, Plaut DC. Systematicity and specialisation in semantics: a computational account of optic aphasia. In: Nineteenth Annual Conference of the Cognitive Science Society. Stanford, CA: Hillsdale, NJ, 1997.

[25] Mummery CJ, Patterson K, Hodges JR, Wise RJS, Price CJ. Functional neuroanatomy of the semantic system: - divisible by what? Journal of Cognitive Neuroscience 1998;10:766-77.

[26] Mummery CJ, Patterson K, Wise RJS, Price CJ, Hodges JR. Disrupted temporal lobe connections in semantic dementia. Brain 1999;122:61-73.

[27] Raven JC. Advanced progressive matrices sets I \& II. London: H. K. Lewis, 1965.

[28] Raven JC. Coloured progressive matrices sets A, AB, B. London: H. K. Lewis, 1962.

[29] Rey, A. L'examen psychologique dans les cas d'encephalopathie traumatique. Arch Psychologie 1941;28:286-340.

[30] Sasanuma S, Monoi H. The syndrome of gogi (word meaning) aphasia. Selective impairment in Kanji processing. Neurology 1975;25:627-32.

[31] Simons JS, Graham KS, Gallon CJ, Patterson K, Hodges JR. Semantic knowledge and episodic memory for faces in semantic dementia. Neuropsychology, submitted. 
[32] Snodgrass JG, Vanderwart M. A standardized set of 260 pictures: norms for name agreement, image agreement, familiarity, and visual complexity. Journal of Experimental Psychology: Human Learning and Memory 1980;6:174-215.

[33] Snowden JS, Goulding PJ, Neary D. Semantic dementia: a form of circumscribed cerebral atrophy. Behavioural Neurology 1989;2:167-82.

[34] Tanabe H, Nakagawa Y, Ikeda M, Hashimoto M, Yamada N, Kazui H, et al. Selective loss of semantic memory for words. In: Ishikawa K, McGaugh JL, Sakata H, editors. Brain processes and memory, 1996. p. 141-52.
[35] Warrington EK. Selective impairment of semantic memory. Quarterly Journal of Experimental Psychology 1975;27:635-57.

[36] Warrington EK, James M. The visual object and space perception battery. Bury St Edmunds: Thames Valley Test Company, 1991.

[37] Warrington EK, McKenna P, Orpwood L. Single word comprehension: a concrete and abstract word synonym test. Neuropsychological Rehabilitation 1998;8:143-54.

[38] Wechsler DA. Wechsler memory scale - revised. San Antonio: Psychological Corporation, 1987. 